\title{
A DIMENSÃO DA QUALIDADE DOS RECURSOS HÍDRICOS NA CONSTRUÇÃO DO BARÔMETRO DASUSTENTABILIDADE
}

BATALHÃO, André Cavalcante da Silva. Mestre em Desenvolvimento Regional e Meio Ambiente pelo Centro Universitário de Araraquara - UNIARA. Especialista em Gestão e Manejo Ambiental na Agroindústria pela Universidade Federal de Lavras - UFLA. E-mail: andreunaerp@ hotmail.com.

TEIXEIRA, Denilson. Professor da Universidade Federal de Goiás - UFG/EEC e pesquisador do Programa de Pós-graduação em Desenvolvimento Regional e Meio Ambiente do Centro Universitário de Araraquara UNIARA. E-mail: dteixeira.ufg@gmail.com.

\section{RESUMO}

Os Indicadores de Sustentabilidade são parâmetros que caracterizam acontecimentos passados, evidenciam retratos situacionais do presente e auxiliam na projeção de cenários futuros em relação à sustentabilidade. Esses instrumentos permitem verificações periódicas do processo de desenvolvimento sustentável em diversasescalas. O Barômetro da Sustentabilidade se encaixa nessa proposta, pois avalia, a partir do tratamento igualitário entre homem e natureza, o grau de sustentabilidade e vem sendo utilizado do âmbito local ao nacional. Dentro dessa perspectiva, o objetivo básico da presente pesquisa foi analisar a dimensão da qualidade dos recursos hídricos na elaboração desse instrumento, tendo como exemplo o município de Ribeirão Preto. A metodologia adotada teve como principal fundamento o Ciclo de Sete Estágios para aplicação do Barômetro da Sustentabilidade. O Barômetro da Sustentabilidade, como ferramenta de avaliação, se revelou útil na contribuição para oentendimento de fenômenos naturais, sendo relevante para a análise dos recursos hídricos em escala local. Esse instrumento é parte componente de um processo de gestão ambiental, não podendo ser considerado de forma isolada. $\mathrm{O}$ Barômetro da Sustentabilidade mostrou que Ribeirão Preto está em um nível razoável em relação aos recursos hídricos analisados e considerados na pesquisa. O índice do tema Água, originado pela ferramenta de avaliação, apresentou o maior valor dentre os outros temas analisados no Subsistema Ecológico para o município, estando em conformidade ambiental e sanitária.

Palavras-chave: Indicadores de sustentabilidade; Recursos hídricos; Barômetro da Sustentabilidade.

\section{THE DIMENSION OF HYDRIC RESOURCES QUALITY IN THE CONSTRUCTION OF THE SUSTAINABILITY BAROMETER}

\section{Abstract}

The Sustainability Indicators are parameters that characterize past events, evidence situational portraits of the present and assist in projecting future scenarios in relation to sustainability. These instruments allow periodic checks of the process of sustainable development at various scales. The Barometer of Sustainability fits this proposal, because, treating men and nature equally, it assesses the degree of sustainability and has been used from local to national scope. Within this perspective, the basic aim of this research was to analyze the quality dimension of water resources in the development of this instrument, taking as an example the city of Ribeirão Preto, SP, Brazil. The adopted methodology had as its main foundation the Seven Stages Cycle for implementing the Barometer of Sustainability. The Barometer of Sustainability as an assessment tool has proved tobe useful in contributing to the understanding of natural phenomena, being relevant to the analysis of water resources at the local level. This tool is a component part of an environmental management process and cannot be considered alone. The Barometer of Sustainability showed that Ribeirão Preto is at a reasonable level in relation to the water resources which were analyzed and considered in the research. The index of the theme Water, originated from the assessment tool, showed the highest value among the other topics discussed in the Ecological Subsystem for the city, being in health and environmental compliance. 
KEYwORDs: Sustainability indicator; Water resources; Sustainability Barometer.

\section{INTRODUÇão}

O processo de urbanização e industrialização nas últimas décadas tem ocorrido sem considerar de forma efetiva os inúmeros impactos negativos gerados nos sistemas ambientais. Nessa perspectiva, os indicadores de sustentabilidade servem como matéria-prima para auxiliar a edificação e manutenção de políticas públicas.

Os indicadores direcionados para o acompanhamento do Desenvolvimento Sustentável podem ser definidos como ferramentas metodológicas que permitem transmitir informações técnicas de uma forma sintética, conservando o significado original dos dados, aceitando, dependendo do objeto estudado, apenas as variáveis que melhor espelham os objetivos da pesquisa. Esses indicadores quantificam e qualificam fenômenos, acontecimentos e realidades complexas, tendo papel relevante nos processos decisórios.

A ferramenta de avaliação escolhida para a presente pesquisa foi o Barômetro da Sustentabilidade - BS, pois permite entender, avaliar e comunicar a sociedade sobre as interações entre homem e bioesfera. O BS é uma metodologia de avaliação da sustentabilidade desenvolvido pelo pesquisador Prescott-Allen, evidenciada a partir da obra The Wellbeing of Nations, em 2001, apoiado pela International Union for Conservation of Nature and Natural Resources IUCN e pelo International Development Research Center-IDRC. A partir dessa ferramenta construímos o nível de sustentabilidade dos recursos hídricos em escala local.

O objetivo principal deste trabalho foi identificar a importância do tema Água para a construção do Barômetro da Sustentabilidade, que é uma ferramenta de acompanhamento do processo de sustentabilidade, tendo como exemplo o município de Ribeirão Preto (SP) - Brasil.

\section{REFERENCIAL TEÓRICO}

O Barômetro da Sustentabilidade faz parte do System Assessment Method - SAM, e trabalha no monitoramento das condições humanas e ecológicas relacionadas ao progresso do desenvolvimento sustentável. Foi criado para aumentar a percepção do conjunto e entender a interação entre sociedade e o meio ambiente, de forma coerente, e para que haja ampla visão desses dois subsistemas. Traz em sua essência a necessidade de integrar e organizar dados para, de forma efetiva, auxiliar a representação do diagnóstico ambiental. Segundo o autor Prescott-Allen (2001), o método está em conformidade com os Princípios de Bellagio para avaliar o Desenvolvimento Sustentável. O método foi projetado em vários níveis geográficos, incluindo nacional, regional, provincial e municipal, mas é menos adequado em escalas muito pequenas (abaixo de $100 \mathrm{~km}^{2}$ ).

Robert Prescott-Allen, em sua obra The Wellbeing of Nations: A Country-by-Country Index of Quality of Life and the Environment, de 2001, traz como hipótese que o Desenvolvimento Sustentável se dá a partir da combinação do bem-estar humano com o bem-estar ecológico. Essa hipótese é evidenciada na metáfora do Ovo do Bem-Estar. Essa metáfora demonstra que: Desenvolvimento sustentável = bemestar humano + bem-estar do ecossistema. Assim como um ovo só é bom se a clara e a gema estão bons, então a sociedade está beme sustentável somente se as pessoas e os ecossistemas estão bem(GUIJT et al. 2001a, p. 10). A Figura 1 permite visualizar a hipótese colocada pelo autor: 


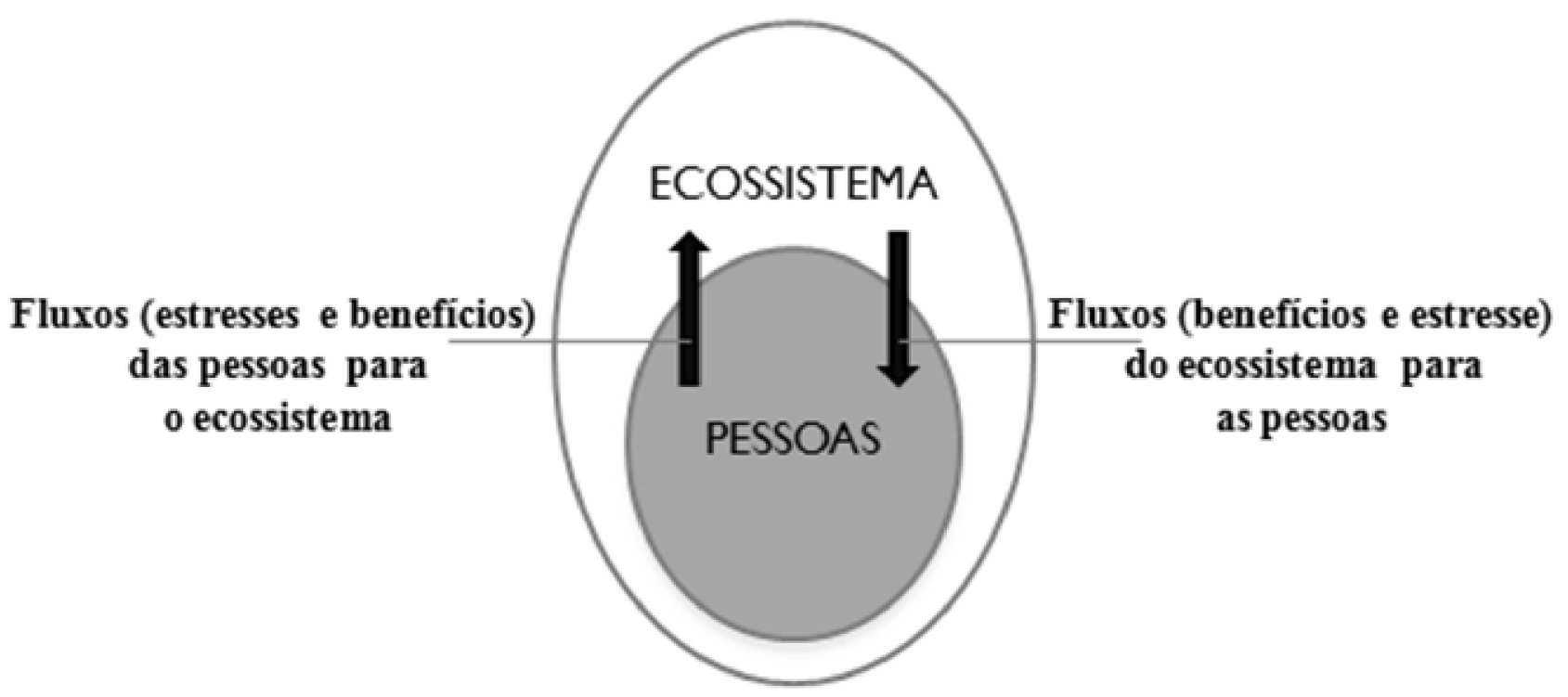

Figura 1 - O Ovo do Bem-Estar, igualdade de tratamento entre pessoas e ecossistema.

Fonte: Guijt et al. (2001c).

\section{IMPORTÂNCIA DO BARÔMETRO}

A ferramenta de avaliação Barômetro da Sustentabilidade se mostra efetiva em escala global a local. Ela contribui para percepção da complexidade de um sistema ou território, facilitando o entendimento dos fenômenos sociais e naturais dentro do universo de pesquisa, provendo o acompanhamento do Desenvolvimento Sustentável e auxiliando a tomada de decisão. O BS pode auxiliar os governos no processo de gestão para diferentes dimensões de análise, pois ele reflete informações do Sistema, Subsistemas, Temas e Indicadores. O BS é parte componente do processo de gestão ambiental, não podendo ser considerado de forma isolada. Cabe destacar que a utilização do BS como uma ferramenta que contribui sensivelmente para a sustentabilidade promove não só a reflexão sobre o real significado do Desenvolvimento Sustentável, como também a continuidade e manutenção da qualidade ambiental local, compatibilizando políticas públicas ambientais também no âmbito municipal.

IMPORTÂNCIA DO TEMA "RECURSOS HÍDRICOS" PARA

\section{o BARÔMETRo}

Em relação aos recursos hídricos, por exemplo, problemas de escassez, qualidade e contaminação das águas vêm afetando significativamente o equilíbrio do ecossistema ambiental, por meio da desestruturação do ambiente físico-químico e da dinâmica natural das comunidades. Para avaliar quão impactado se encontra o ecossistema ambiental, tem sido utilizada a medição das alterações nas concentrações das variáveis físicas, químicas e microbiológicas (coliformes totais e fecais), que se constituem como ferramentas fundamentais no monitoramento, na classificação e no enquadramento de rios e córregos em classes de qualidade de água e padrões de potabilidade e balneabilidade humanas (GOULART; CALLISTO, 2003). Assim, pode-se definir a qualidade de um ambiente aquático como um conjunto de concentrações, especificações e elementos físicos de substâncias orgânicas e inorgânicas e da composição e condição da biota aquática em um corpo d'água (GASTALDINI; MENDONÇA, 2001). Além disso, o uso e a ocupação do solo influenciam na qualidade e na quantidade dos recursos hídricos de uma bacia hidrográfica, tornando fundamental sua 
análise, pois as alterações geradas decorrem, principalmente, de atividades antrópicas, como desmatamento, reflorestamento e urbanização, promovendo impactos de grande importância sobre o comportamento hidrológico da bacia e, em particular, no que se refere ao escoamento superficial. O Barômetro da Sustentabilidade, a partir de suas escalas de desempenho, em que são estabelecidos os limites para cada grau de sustentabilidade, propicia um diagnóstico analítico de dados quantitativos da água e proporciona um retrato qualitativo da variável analisada.

\section{Metodologia}

A metodologia adotada nesta pesquisa é fundamentada na aplicação da ferramenta de avaliação da sustentabilidade, Barômetro da Sustentabilidade, com características exploratória e descritiva, a partir de uma localidade delimitada como o universo da investigação (Ribeirão Preto, Estado de São Paulo, Brasil), e recorte temporal 2010-2011 para o tema Água.

A seleção dos indicadores para compor o Barômetro da Sustentabilidade se dá a partir de um método hierarquizado, composto por sete estágios, que ajuda a justificar a importância e relevância dos indicadores escolhidos em relação ao conceito de Desenvolvimento Sustentável, tornando perceptíveis deficiências e necessidades do espaço físico considerado no estudo. Os sete estágios estão apresentados na Figura 2. 


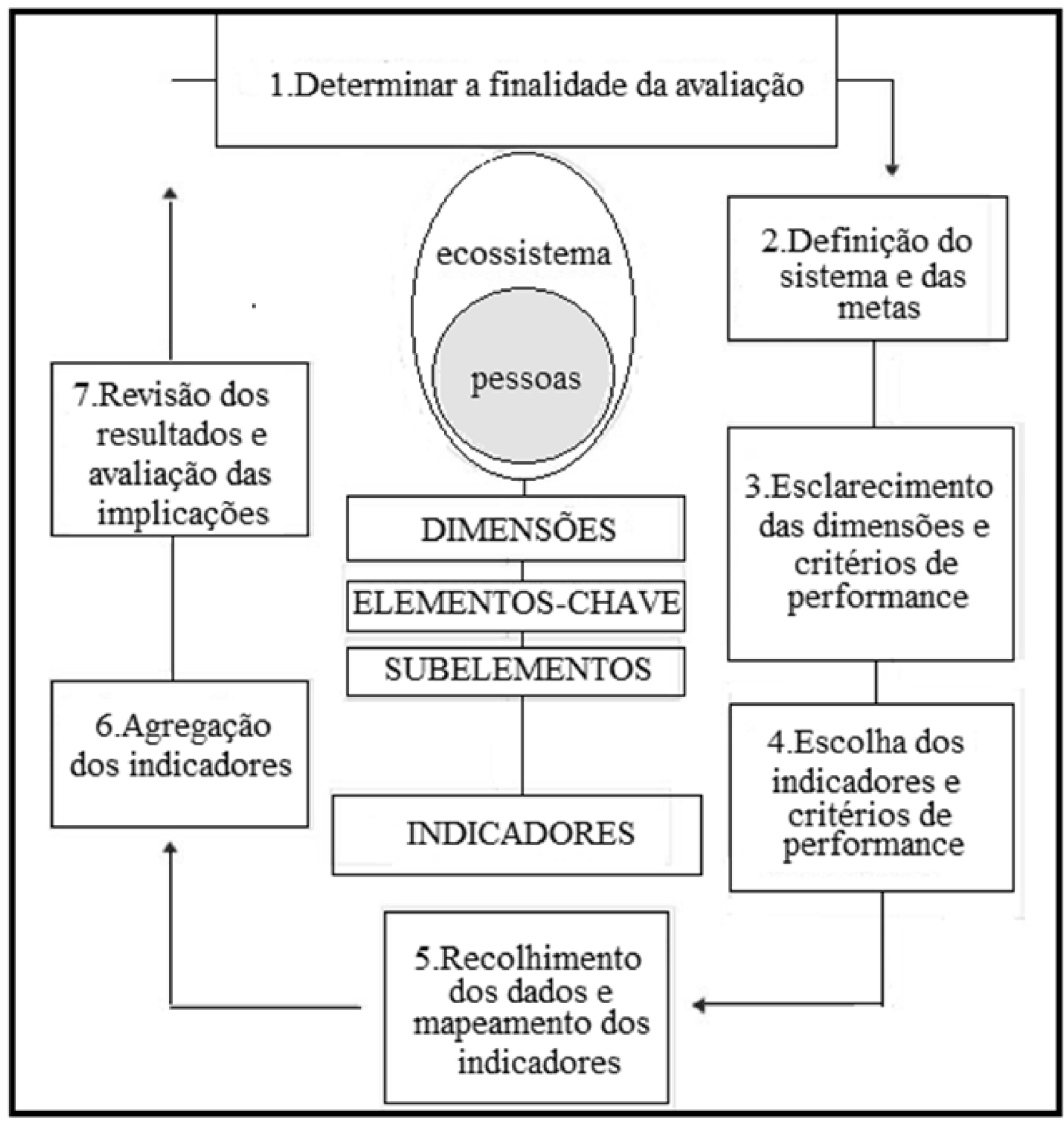

Figura 2 - Ciclo de sete estágios para aplicação do Barômetro da Sustentabilidade.

Fonte: Guijt et al. (2001c). 
Dentro os procedimentos de análise das variáveis do tema Água, considerando o sistema (objeto) adotado na pesquisa, foram levados em consideração a disponibilidade dos dados e o que vai ser medido pelos indicadores escolhidos. Assim, conseguimos clarificar as dimensões de sustentabilidade e agrupar o conceito que cada indicador traz isoladamente, gerando um índice. Com a utilização do Ciclo de Sete Estágios podem ser analisados os elementos e subelementos que requerem atenção prioritária, fornecendo informações das causas dos principais problemas e quais ações são necessárias como resposta. O Barômetro da Sustentabilidade fornece fotografias das dimensões ecológicas e humanas, que são complementares e exercem impacto uma sobre a outra no processo de sustentabilidade, sem favorecer nenhumas das duas (Subsistema Humano e Ecológico).

Atransposição do valor numérico do indicador para a Escala do Barômetro da Sustentabilidade é feita por meio de uma fórmula de interpolação linear simples (KRONEMBERGER; CARVALHO; CLEVELÁRIO JUNIOR, 2004), que indica o intervalo (dimensão) de qualidade em que determinado indicador está alocado:

$$
\mathrm{BS}_{\mathrm{X}}=\left\{\left[\frac{\left(D L_{A}-D L_{x}\right) x\left(B S_{A}-B S_{P}\right)}{\left(D L_{A}-D L_{P}\right)}\right] x(-1)\right\}+B S_{A}
$$

Onde: $\mathrm{A}=$ limite anterior do intervalo que contém $\mathrm{X}$. $\mathrm{P}=$ limite posterior do intervalo que contém $\mathrm{X}$.

Depois de feita a transposição para a escala do BS, visualizamos em qual setor (dimensão) de sustentabilidade o indicador se encaixa. A Tabela 1 demonstra o alcance dos setores do BS. 
Tabela 1 - Os cinco setores do Barômetro da Sustentabilidade.

\begin{tabular}{|c|c|c|c|}
\hline & Pontos & & \\
\hline Setor & Alcance & Topo & Definição \\
\hline Bom & $100-81$ & 100 & $\begin{array}{c}\text { Desempenho desejável, objetivo plenamente } \\
\text { alcançado. }\end{array}$ \\
\hline Razoável & $80-61$ & 80 & Desempenho aceitável, objetivo quase alcançado. \\
\hline Médio & $60-41$ & 60 & Desempenho ne utro ou de transição. \\
\hline Pobre & $40-21$ & 40 & Desempenho indesejável. \\
\hline Ruim & $20-1$ & 20 & Desempenho inaceitável. \\
\hline Base & 0 & 0 & Base da escala. \\
\hline
\end{tabular}

Fonte: Modificado de Prescott-Allen, 2001.

As variáveis consideradas na presente pesquisa, no tema Água, são: o IQA (Índice de Qualidade de Água), IVA (Índice de Qualidade de Proteção da Vida Aquática) e IPAS (Indicador de Potabilidade de Âgua Subterrânea), como apresentado na Tabela 2. 
Tabela 2 - Tema, Indicadores, Fontes para elaboração das Escalas de Desempenho e ano das informações.

\begin{tabular}{|c|c|c|c|}
\hline Tema & Indicadores & $\begin{array}{c}\text { Fonte e referência para elaboração } \\
\text { da Escala de Desempenho }\end{array}$ & $\begin{array}{c}\text { Ano da } \\
\text { informação }\end{array}$ \\
\hline \multirow{3}{*}{$\underbrace{\longleftarrow}$} & $\begin{array}{c}\text { IQA (Índice de Qualidade } \\
\text { de Água) }\end{array}$ & $\begin{array}{l}\text { Fonte: CETESB (2012). O IQA varia em } \\
\text { uma escala de } 0 \text { a } 100 \text { (CETESB, 2012), } \\
\text { mes mo critério adotado para escala de } \\
\text { desempenho. }\end{array}$ & 2011 \\
\hline & $\begin{array}{l}\text { IVA (Índice de Qualidade } \\
\text { de Proteção da Vida } \\
\text { Aquática) }\end{array}$ & $\begin{array}{l}\text { Fonte: CETESB (2012). Escala de } \\
\text { desempenho elaborada de acordo com as } \\
\text { faixas de classificação do IVA. }\end{array}$ & 2011 \\
\hline & $\begin{array}{c}\text { IPAS (Indicador de } \\
\text { Potabilidade das Águas } \\
\text { Subterrâneas) }\end{array}$ & $\begin{array}{l}\text { Fonte: SÃO PAULO (2011). Escala de } \\
\text { desempenho enquadrada nas faixas de } \\
\text { qualidade consolidadas para o IPAS. }\end{array}$ & 2010 \\
\hline
\end{tabular}

Fonte: Elaborado pelos autores.

Resultados E DISCUSSÃo

O tema Água apresentou o valor de 71,5 na Escala do BS, considerado como potencialmente sustentável. Dentre os partícipes desse tema, estão os indicadores IQA e IPAS, com melhor e pior desempenho, respectivamente. A Tabela 3 aponta onde está localizado o nível de sustentabilidade, de acordo com a Escala do Barômetro da Sustentabilidade, os indicadores para Ribeirão Preto e os seus limites de intervalo para o tema Água. 
Tabela 3 - Escalas de Desempenho dos Indicadores de Desenvolvimento Sustentável de Ribeirão Preto-SP e sua associação com a Escala do Barômetro da Sustentabilidade.

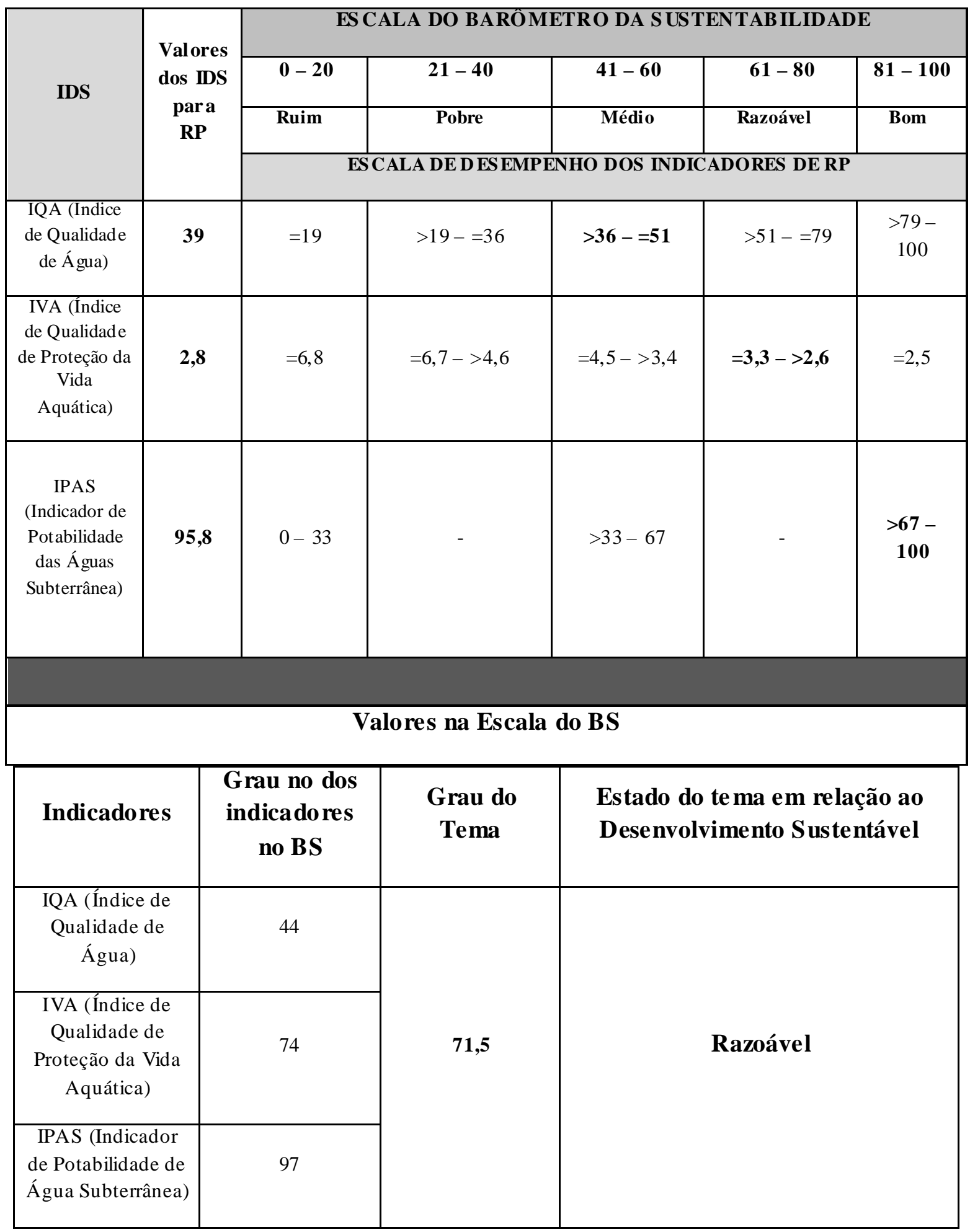

Fonte: Elaborado pelos autores. 
A representação gráfica (Figura 3) mostra o desempenho do tema Água, na escala do Barômetro

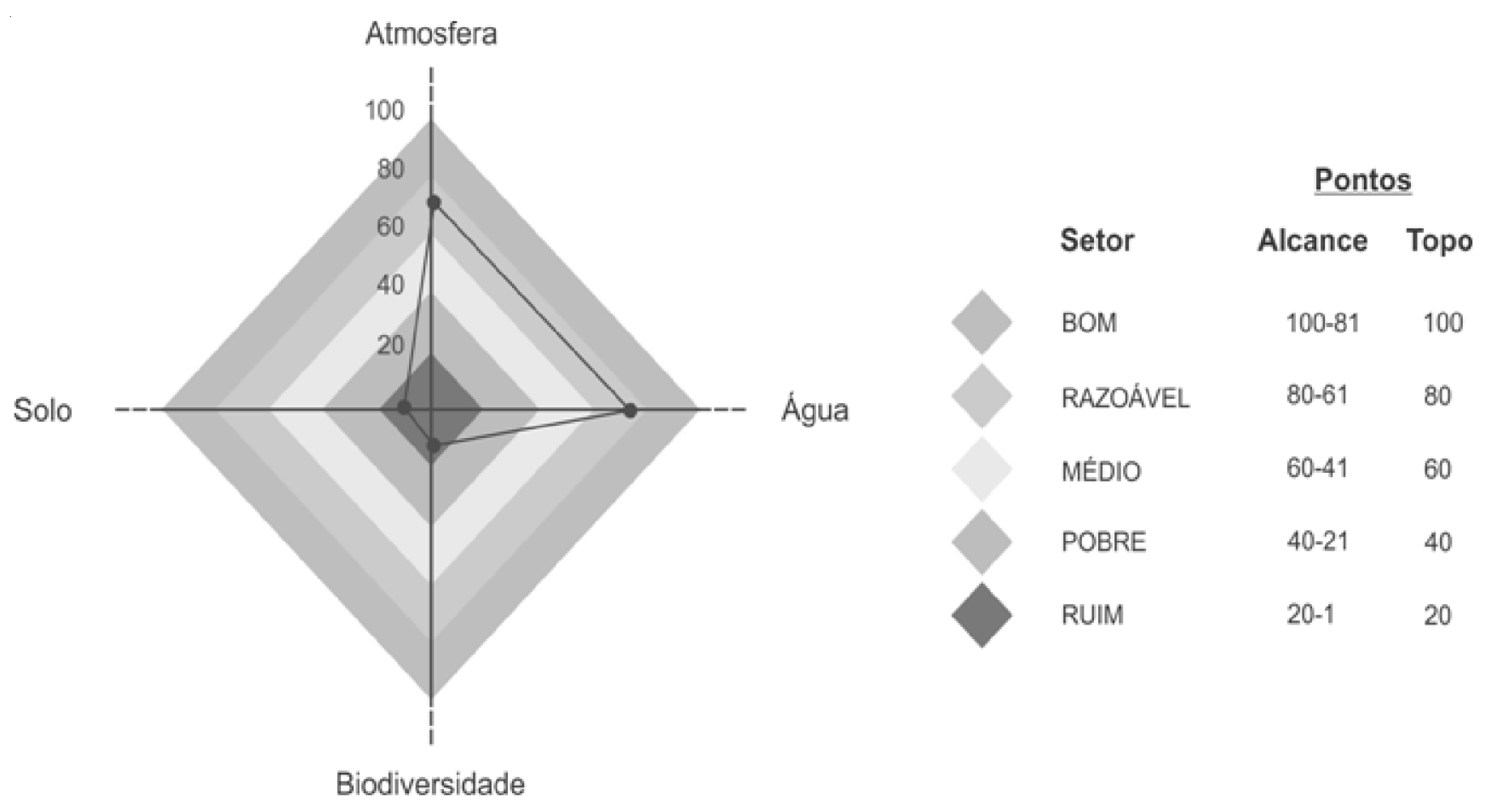

da Sustentabilidade, no Subsistema Ecológico, na cidade de Ribeirão Preto.

Figura 3 - Desempenho dos temas no Subsistema Ecológico na Escala do BS.

Fonte: Elaborado pelos autores.

A qualidade dos recursos hídricos, a partir das variáveis adotadas nesta pesquisa, apresentou-se aceitável, ou seja, possuem significados ambientais e sanitários admissíveis na avaliação do ambiente aquático. O tema Água está inserido na faixa de sustentabilidade "razoável" na escala do Barômetro da Sustentabilidade (grau 71,5), influenciando positivamente o desempenho do subsistema ecológico.

O monitoramento da qualidade das águas interiores doces é composto por redes de amostragem manual e automática, que têm como foco um diagnóstico dos usos múltiplos dos recursos hídricos. A análise das distribuições geográficas dos pontos por UGRHI, município e corpo hídrico constitui-se em ferramenta para subsidiar a avaliação dos rios e reservatórios (CETESB, 2012). Segundo a CETESB (2012), a rede de água doce é constituída por 354 pontos de amostragem. Foram incluídos 12 novos pontos de coleta e excluídos 2 pontos, resultando em um incremento de 10 pontos de amostragem. $O$ ponto de coleta escolhido para a presente pesquisa está localizado emum manancial no município de Ribeirão Preto-SP, Lat. S 210513 Long. W 4748 56, código CETESB RIPE04900, a jusante da ETE de Ribeirão Preto (CETESB, 2012).

Por estar a jusante da ETE, o RIPE04900 fornece um melhor retrato do impacto que o ecossistema ali localizado pode sofrer, mostrando-se um indicador fundamental para o entendimento das necessidades ambientais do local. De acordo coma CETESB (2012), a rede de monitoramento empregada no ponto de coleta escolhido é denominada Rede Básica, tipo de monitoramento utilizado em $84 \%$ dos pontos de rede de água doce em 2011, e tem como objetivo fornecer 
um diagnóstico geral dos recursos hídricos, caracterizando variáveis físicas, químicas e biológicas. A média do IQA do RIPE04900, em 2011, foi de 39, e de 44 na escala do BS, resultado considerado como intermediário. O Gráfico 1 demonstra a distribuição de valores do IQA nos meses considerados pela CETESB no ano de 2011 (mais recentes valores divulgados), bem como o melhor desempenho do mês de novembro e o ponto crítico do ano, que foi no mês de maio.

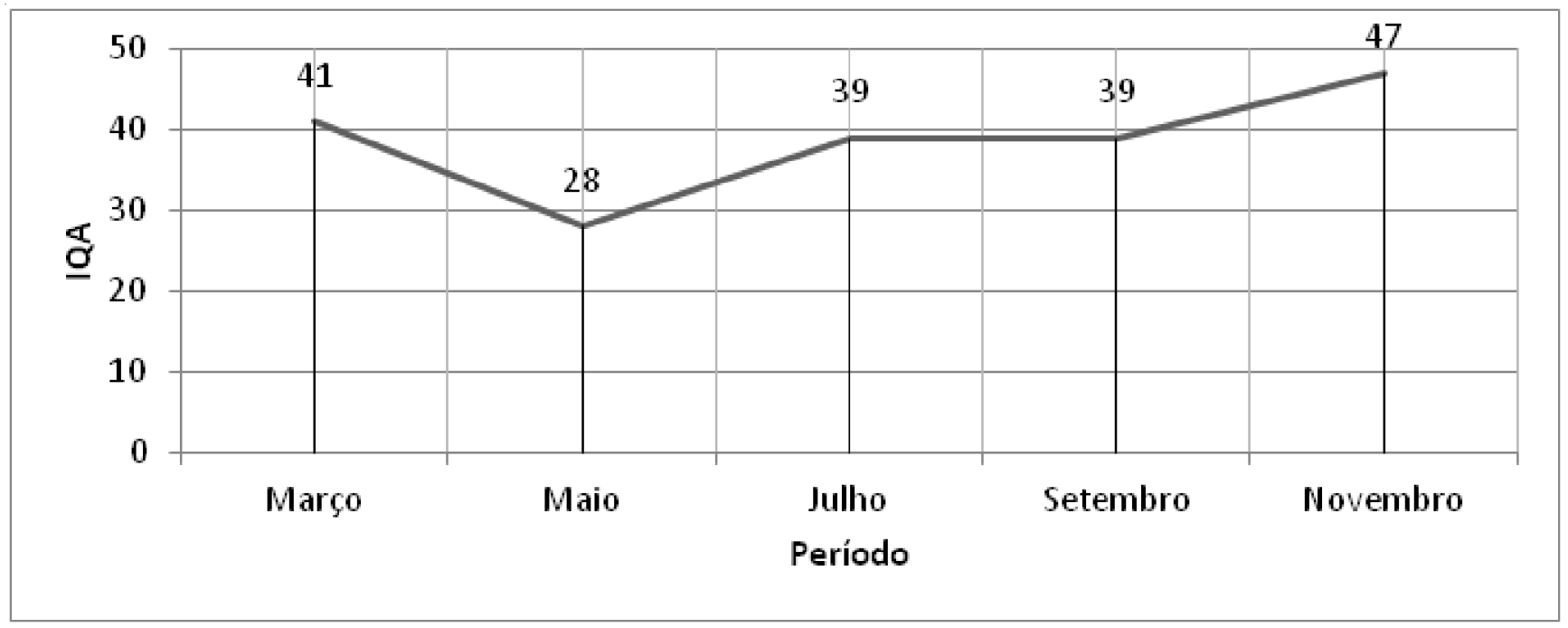

Gráfico 1 - IQA do RIPE04900 em 2011.

Fonte: Elaborado pelo autor com dados da CETESB, 2012.

O Estado de São Paulo apresentou uma distribuição percentual das categorias do IQA, na UGRHI 4 Pardo, onde o ponto de coleta RIPE04900 está inserido, de $83 \%$ como bom e $17 \%$ como regular em 2011 (CETESB, 2012). Em um estudo de escala nacional, realizado pelo IBGE em 2010, que selecionou corpos d'agua localizados em algumas unidades da federação (Pernambuco, Minas Gerais, Rio de Janeiro, São Paulo, Paraná e Rio Grande do Sul), podemos encontrar dois corpos d'agua que apresentam valores abaixo e igual ao do IQA encontrado para a cidade de Ribeirão Preto: Zona Metropolitana/Alto Tietê, em São Paulo, onde de 1992 a 2008 seu IQA não passou do valor de 33,4, que foi o maior índice alcançado, no ano de 1996. O corpo d’agua Rio Iguaçu/Zona Metropolitana, no Paraná, teve seu último valor de IQA divulgado de 31, em 2006, um declínio de oito pontos em relação a 2005, ano em que o IQA de 2011 do RIPE04900 foi semelhante ao corpo d'agua paranaense (IBGE, 2010).

A falta de saneamento básico é um dos maiores problemas ambientais e sociais do Brasil, pois o baixo percentual de tratamento dos esgotos coletados e lançados em corpos d'água se reflete no alto valor de DBO e baixo IQA dos rios que cortam grandes áreas urbanas, atravessam zonas industrializadas, ou passam por muitas cidades de médio e grande portes. A contaminação de rios por efluentes domésticos, industriais e resíduos sólidos encarece o tratamento de água para abastecimento público e começa a gerar situações de escassez de disponibilidade de água de qualidade em áreas com abundantes recursos hídricos (IBGE, 2010).

O IPAS teve o desempenho de 97 pontos na escala do BS, considerado potencialmente sustentável, contribuindo para o bom desempenho do tema no Subsistema. O IPAS da UGRHI 4 (Tabela 8, página 110) Pardo, da qual Ribeirão Preto é componente, 
atingiu em sua última análise (em 2010) o valor de 95,8\%, o quarto maior valor do Estado de São Paulo. Para análise de água subterrânea no Estado de São Paulo em 2010, foram monitorados 235 poços distribuídos pelas UGRHIs, totalizando 456 amostras ao longo do ano, e a UGRHI 4 - Pardo possuía 12 pontos de amostragem (SÃO PAULO, 2012). Dentre os pontos monitorados, o IPAS no Estado, a partir da proporção de amostras de água subterrânea bruta, foi classificado como potável, ou seja, em conformidade com os padrões de potabilidade do Ministério da Saúde (SÃO PAULO, 2011). A partir dos dados do índice de 2006 a 2010, chegou-se a uma média do IPAS para o Estado de São Paulo de 81,16\%, considerada como um bom padrão de qualidade. O Gráfico 2 apresenta uma comparação do IPAS por UGRHI, em 2010.

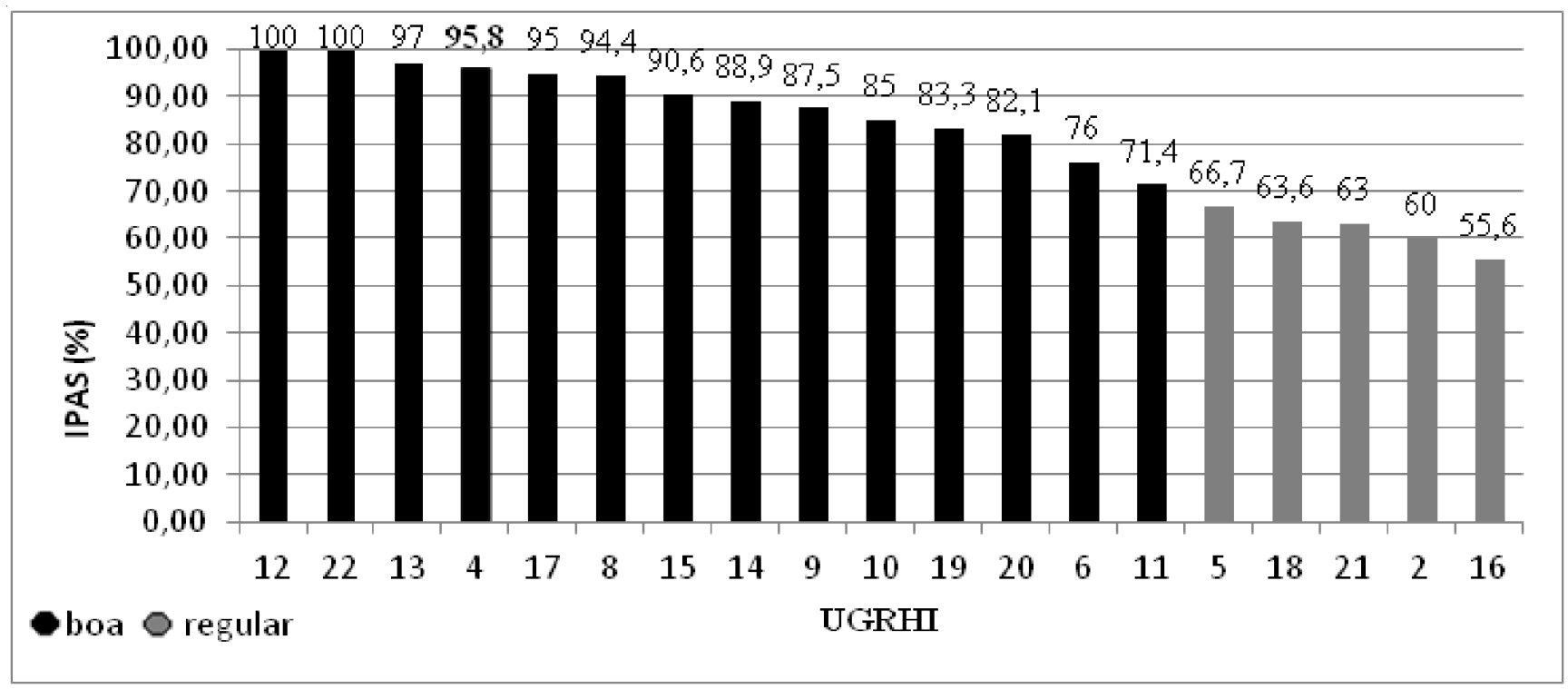

Gráfico 2 - Comparação do IPAS por UGRHI no Estado de São Paulo em 2010. Fonte: São Paulo, 2011.

Analisando o desempenho das UGRHIs, em 2010, último ano em que foram geradas as informações, no Estado de São Paulo observou-se que as UGRHI 2 (Paraíba do Sul) e 16 (Tietê/Batalha) tiveram os piores índices de potabilidade de água subterrânea, com $60 \%$ e 55,6\% respectivamente; entretanto, permanecem enquadradas com desempenho regular. Destacam-se ainda, na mesma faixa, as UGRHI 5 (Piracicaba/ Capivari/Jundiaí), 18 (São José dos Dourados) e 21 (Peixe). As UGRHIs 12 (Baixo Pardo/Grande) e 22
(Pontal do Paranapanema) atingiram $100 \%$ das amostras dentro dos padrões de potabilidade. É importante salientar que a distribuição dos pontos de amostragem é desigual nas UGRHIs, uma vez que existem UGRHIs com maior e menor número de pontos de amostragem. De 2006 a 2010, o IPAS do Estado de São Paulo apresentou seu maior índice em $2006(86,9 \%)$ e o menor em 2007 (77,7\%) (SÃO PAULO, 2011), percebido com a apresentação do Gráfico 3. 


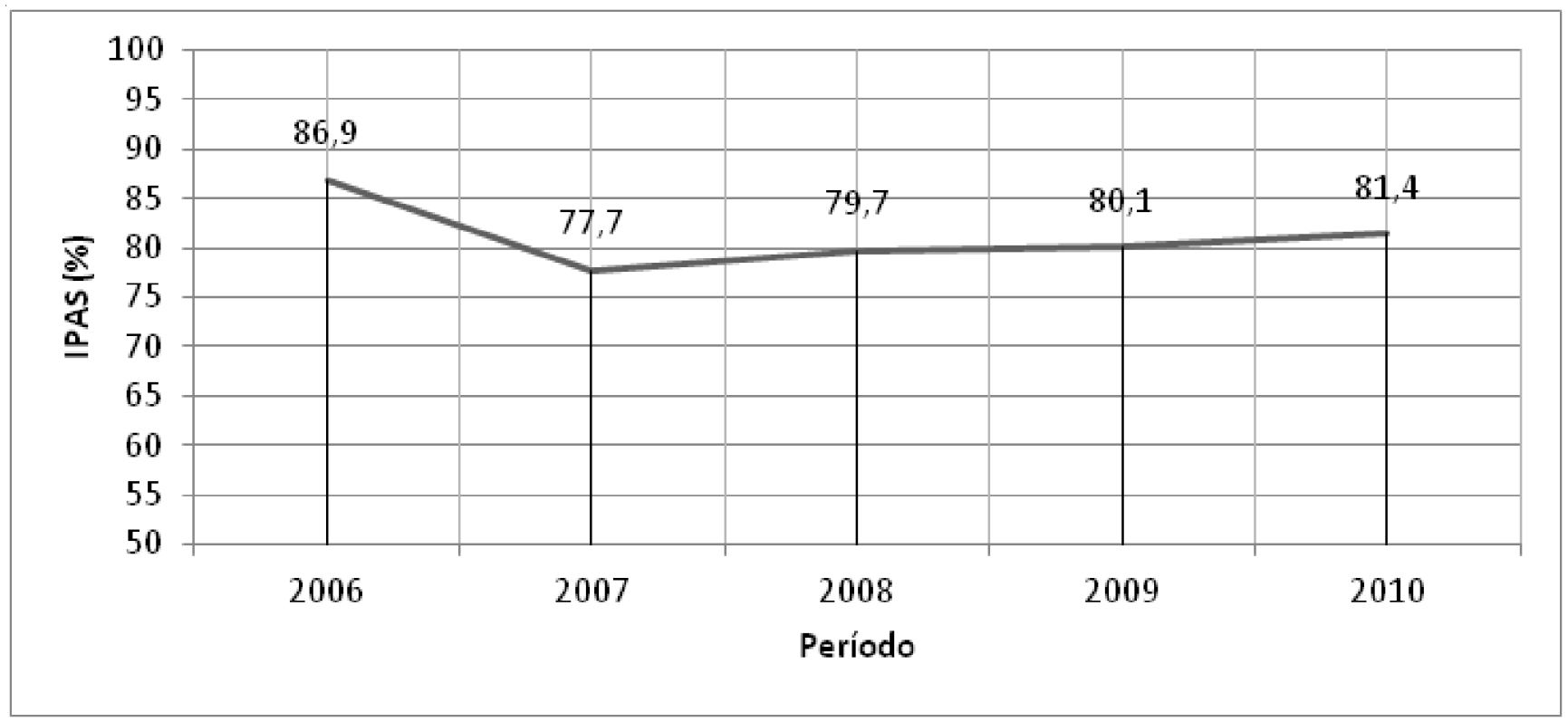

Gráfico 3 - Evolução do IPAS do Estado de São Paulo, de 2006 a 2010.

Fonte: São Paulo, 2011.

Pode-se perceber uma leve, mas gradual, evolução desse indicador a partir de 2007, período no qual a política ambiental paulista se tornou mais efetiva, com a formulação de Projetos Ambientais Estratégicos PAE, que estabelece um modelo organizacional de natureza matricial, integrando as diversas áreas de atuação da Secretaria de Meio Ambiente do Estado de São Paulo (SÃO PAULO, 2010). Dentre os 21 projetos elaborados para o cumprimento das metas estabelecidas, estão relacionados ao tema Água a preocupação com os aquíferos e o esgoto tratado. De acordo com São Paulo (2011), a meta para do índice para 2020 é alcançar um valor acima de $85 \%$.

Dentre outros estudos realizados a partir do Barômetro da Sustentabilidade, dois foram desenvolvidos a partir de localidades. Tratando-se do tema Água, as cidades de João Pessoa e Campina Grande, ambas cidades paraibanas, apresentaram índices temáticos na mesma faixa de sustentabilidade de Ribeirão Preto. João Pessoa apresentou o índice temático de 76,39, considerado como razoável ou potencialmente sustentável para o tema Água (LUCENA; CAVALCANTE; CÂNDIDO, 2011), e
Campina Grande apresentou o índice 79,96 (BARROS; AMORIM; CÂNDIDO, 2009).

\section{Conclusões}

O Barômetro da Sustentabilidade é parte componente de um processo de gestão ambiental, não podendo ser considerado de forma isolada. O BS pode ser utilizado para o aprimoramento de planejamentos direcionados aos recursos hídricos e na elaboração de planos estratégicos de bacias hidrográficas. Isso contribui para a identificação de áreas críticas, o que ajuda a minimizar os impactos negativos (degradação) e gera matéria-prima para a elaboração de políticas públicas que amparem e preservem a qualidade da água para o consumo humano e animal.

Esse instrumento mostrou que Ribeirão Preto está em um nível razoável em relação aos recursos hídricos analisados e considerados na pesquisa. $\mathrm{O}$ índice do tema Água, originado pela ferramenta de avaliação, apresentou o maior valor dentre os temas considerados e analisados na pesquisa (Atmosfera, Solo e Biodiversidade) no Subsistema Ecológico para o município. 
As intervenções governamentais devem ser orientadas para o equilíbrio entre bem-estar humano e ecológico, e assegurar que a água seja disponibilizada continuamente e com um nível satisfatório de qualidade e segurança. A aplicação do BS fornece informações criteriosas, que são um passo fundamental para a conscientização da sociedade e da gestão do poder público em relação à vulnerabilidade dos recursos hídricos e à oferta de água na localidade. Com a edificação de bases informacionais contendo dados dos recursos hídricos, podemos promover a conservação e o uso sustentável da água, internalizando tais questões nas políticas públicas do município, tratando a questão de forma participativa.

\section{REFERÊNCIAS}

BARROS, R. A.; AMORIM, B. P.; CÂNDIDO, G. A. Análise da Sustentabilidade Municipal: Uma aplicação do Barometer of Sustainability em Campina Grande - PB. Engema - XI Encontro Nacional e I Encontro Internacional sobre Gestão Empresarial e Meio Ambiente, São Paulo, 2009. 15 p.

\section{CETESB - COMPANHIA AMBIENTALDO} ESTADO DE SÃO PAULO. Qualidade das águas superficiais no Estado de São Paulo 2011. São Paulo: Cetesb, 2012. 356 p. Disponível em: Acesso em: < http://www.cetesb.sp.gov.br/agua/ aguas-superficiais/35-publicacoes-/-relatorios $>$. Acesso em: 24 jul. 2013.

GASTALDINI, M. C. C.; MENDONÇA, A. S. F. Conceitos para a avaliação da qualidade da água. In: PAIVA, J. B. D.; PAIVA, E. M. C. D. Hidrologia aplicada à gestão de pequenas bacias hidrográficas. Porto Alegre: ABRH, 2001. p. 428451.

GOULART, M. D. C.; CALLISTO, M. Bioindicadores de qualidade da água como ferramenta em estudos de impacto ambiental.
Revista da FAPAM, ano 2, n. $^{\circ}$ 1, 2003. p. 153-164.

GUIJT, I. M. et al. IUCN resource kit for sustainable assessment: Parte A - Overview (x, 83 p.), Parte B - Facilitators Materials (viii, 172 p.), Parte C - Slides for Facilitators (vi, 92 p.) : IUCN Monitoring and Evaluation Initiative, Gland, Switzerland, 2001.

\section{IBGE - INSTITUTO BRASILEIRO DE} GEOGRAFIA E ESTATÍSTICA. Indicadores de Desenvolvimento Sustentável. Rio de Janeiro: IBGE, 2010. Disponível em: < http:// www.ibge.gov.br/home/geociencias/ recursosnaturais/ids/ids2010.pdf > . Acesso em: 01 jun. 2012.

KRONEMBERGER, D. M. P.; CARVALHO, C. N. de; CLEVELÁRIO JUNIOR, J. Indicadores de Sustentabilidade em Pequenas Bacias Hidrográficas: uma aplicação do "Barômetro da Sustentabilidade" à Bacia do Jurumirim (Angra dos Reis, RJ). Revista Geochimica Brasiliensis, São Paulo, v. 18, n. 2, p. 86-92, 2004.

\section{LUCENA, A. D., CAVALCANTE, J. N.;}

CÂNDIDO, G. A. Sustentabilidade do Município de João Pessoa: uma aplicação do Barômetro da Sustentabilidade. Revista Brasileira de Gestão e Desenvolvimento Regional, Taubaté, v. 7, n. 1, 2011. p. 19-49.

PRESCOTT-ALLEN, R. The wellbeing of nations: a country-by-country index of quality of life and the environment. Washington: Island Press, 2001. 342 p.

\section{SÃO PAULO. Painel da Qualidade Ambiental} 2011. São Paulo: Secretaria do Meio Ambiente/ Coordenadoria de Planejamento Ambiental, 2011. $132 \mathrm{p}$. 
Política Ambiental Paulista 20072010: Relatório de cumprimento de metas e resultados. São Paulo: Secretaria do Meio Ambiente, 2010. 112 p.
ZEE - Zoneamento ecológicoeconômico: base para o desenvolvimento sustentável do Estado de São Paulo. São Paulo: Secretaria do Meio Ambiente, 2012. 224 p. 
